\title{
Indoor air quality assessment in a school building in Chennai City, India
}

\author{
S. M. Shiva Nagendra \& P. Sri Harika \\ Department of Civil Engineering, Environmental and Water Resources \\ Engineering Division, Indian Institute of Technology Madras, India
}

\begin{abstract}
During recent years, concerns over the effects of poor indoor air quality (IAQ) have been increased and wide spectrums of symptoms/illnesses are related to indoor air pollution in many urban centers of the world. In India, it is estimated that about half a million women and children die per year due to indoor air pollution. Therefore, maintaining an acceptable IAQ is important in places such as schools, corporate office buildings, hospitals and houses. It is hypothesized that the higher indoor pollutant concentrations of the buildings located near busy traffic roads are mostly influenced by elevated outdoor vehicular pollutant concentrations. In this paper an attempt has been made to analyze the indoor air quality of a naturally ventilated school building, Kendriya Vidyalaya, located in the Central Leather Research Institute (CLRI), Chennai, India. This building is located close to an urban road with heavy traffic flow, within a range of $100 \mathrm{~m}$ from the busy traffic junction. The indoor pollutants, namely carbon monoxide (CO) and carbon dioxide $\left(\mathrm{CO}_{2}\right)$, along with meteorological parameters such as temperature and relative humidity, have been measured inside the school building. The vehicular pollutant $\mathrm{CO}$ has also been measured at the road side to develop the indoor and outdoor $\mathrm{CO}$ relationship. Further, a questionnaire survey has also been conducted to evaluate the general environmental conditions (sick building syndrome) of the school building.

The result indicated that hourly the $\mathrm{CO}_{2}$ concentration inside the school room is $927 \mathrm{ppm}$ during morning working hours (10.00a.m). This concentration is close to standard value of $1000 \mathrm{ppm}$ specified by the National Institute for Occupational Safety and Health (NIOSH), USA. The measured CO concentrations inside the school building are well within the standard. During
\end{abstract}


peak hour traffic flow on the adjacent road, a high level $\mathrm{CO}$ concentration has been observed inside the school building.

The questionnaire survey at school shows that nearly $50 \%$ of students are suffering from minor health problems.

Keywords: indoor air pollution, natural ventilation, monitoring, meteorology, school building, traffic, outdoor air pollutants, exposure, health effects, questionnaire survey, IAQ standard.

\section{Introduction}

In recent years, indoor air quality (IAQ) has received increasing concern due to its adverse effects on human health. There is consistent evidence that indoor air pollution increases the risk of chronic obstructive pulmonary disease and acute respiratory infections in childhood, especially in children aged less than 5 years in developing countries. In 1992, the World Bank designated indoor air pollution in developing countries as one of the four most critical global environmental problems [1]. According to the World Health Report 2002 [2], indoor air pollution is responsible for $2.7 \%$ of the global burden of diseases. In India, it has been estimated that about half a million women and children die each year from indoor air pollution [3].

Inhalation is the main route of exposure to indoor air pollutants. Exposure by inhalation directly affects the respiratory, nervous and cardiovascular systems of humans, resulting in impaired pulmonary functions, sickness, and even death. In a day people spend about $90 \%$ of their time in indoors and the rest outdoors. Therefore, exposure to higher concentrations of indoor air pollutants has frequently been attributed as a cause of sick building syndrome (SBS) and chronic health diseases [4]. India has among the largest burden of disease due to the use of dirty household fuels. Out of total deaths in developed countries, $28 \%$ are due to indoor air pollution [3]. However, the actual human exposures are often difficult to quantify. This is largely because the behavior and activity patterns of each individual can strongly affect their levels of exposure.

Indoor air pollutants emanate from a range of sources. They are broadly classified into two types, namely biological and non-biological sources. The sources of indoor air pollutants may be inside the building, or they may be transported from outside. Several factors influence the IAQ of buildings: the rate of indoor air exchange with the outdoor air, the indoor pollutant concentration, the indoor source emissions rate, the rate of infiltration from soil gases and the rate of removal in the indoor environment. The air exchange rate influences the concentration of indoor pollutants in two ways. When the outdoor air pollutant concentrations are much lower than the indoor concentrations, higher air exchange rates help to lower the indoor air pollutants level. On the other hand, when outdoor pollutant concentrations are higher than the indoor, the high air exchange rate will bring elevated outdoor air pollutant concentration into the building. At lower exchange rates, pollutants released from sources inside the building can contribute to higher levels of indoor pollutants. 
In the past, several studies report that people living in buildings located close to major roads might be having chronic health effects due to the poor indoor air quality induced from the outdoor pollutant concentrations. The WHO indicated that the air inside the buildings is more polluted than the outdoor air in most of the megacities (population greater than 10 millions). Since people spend $90 \%$ of their time indoors, the health risks are higher (especially in children, women and old people) due to exposure to indoor pollution.

In the present paper an attempt has been made to analyze the indoor air quality of a naturally ventilated school building, Kendriya Vidyalaya, located in the Central Leather Research Institute, Chennai, India.

\section{Indoor air quality}

IAQ refers to the physical, chemical, and biological characteristics of air inside the indoor environment, e.g., home, building, or an institution or commercial facility. During the recent past, exposure to indoor air pollutants is believed to have increased due to a variety of factors, including the construction of more tightly sealed buildings, reduced ventilation rates to save energy, the use of synthetic building materials and furnishings, and the use of chemically formulated personal care products, pesticides, and household cleaners. It is estimated that indoor air pollution is responsible for the death of 1.6 million people per year worldwide, i.e. one death every 20 seconds. The WHO has reported indoor air pollution as the $8^{\text {th }}$ most important risk factors to the burden of disease and that it is responsible for $2.7 \%$ of the global burden of disease. In developing countries, indoor pollution is responsible for $3.7 \%$ of the overall disease burden, making it the most lethal killer after malnutrition, unsafe sex and lack of safe water and sanitation [2].

Sick building syndrome (SBS) is a situation in which occupants of a building experience acute health effects that seem to be linked to time spent in a building, but no specific illness or cause can be identified. The complaints may be localized in a particular room or zone, or may be widespread throughout the building. Building occupants complain of symptoms associated with acute discomfort. These symptoms include headaches; eye, nose, and throat irritation; a dry cough; dry or itchy skin; dizziness and nausea; difficulty in concentrating; fatigue; and sensitivity to odors. With SBS, no clinically defined disease or specific chemical or biological contaminant can be determined as the cause of the symptoms. Most of the complainants feel relief soon after leaving the building. SBS reduces worker productivity and may also increase absenteeism. Specific causes of SBS remain unknown. Factors such as pollutant concentration from outdoor and indoor sources, microbes and inadequate ventilation may act in combination or may supplement other complaints, such as inadequate temperature, humidity, or lighting.

Maintaining good indoor air quality requires attention to the building's heating, ventilation, and air conditioning (HVAC) system; the design and layout 
of the space; and pollutant source management. HVAC systems can even act as sources of pollutants, when ventilation air filters become contaminated with dirt and/or moisture, or microbial growth inside of air ducts.

Health effects due to indoor air pollutants may be short- as well as long-term. Short-term problems include burning eyes, skin irritation and headaches. Long-term health problems have a longer latency period or are chronic in nature. The predominant health effect associated with exposure to elevated levels of radon is lung cancer. The causal agents of illnesses and stress in buildings may be chemical, physical, biological, psychosomatic or the synergetic effects of one or all of these agents. Indoor air pollutants have the potential to cause transient morbidity, disability, disease and even death in extreme cases [5]. The magnitude and duration of detrimental health effects are influenced by the time of exposure, concentration, presence of a preexisting unhealthy condition and age. Figure 1 shows that there is enough evidence to accept that indoor air pollution in India is responsible for a high degree of morbidity and mortality, warranting immediate steps for intervention.

\section{Indoor air quality of schools and kindergartens}

Fischer et al. [6] reported higher indoor and outdoor air concentrations of volatile organic compounds (VOCs) and particulate matters for homes located near heavy traffic areas than for homes near lower-traffic areas. The study concludes

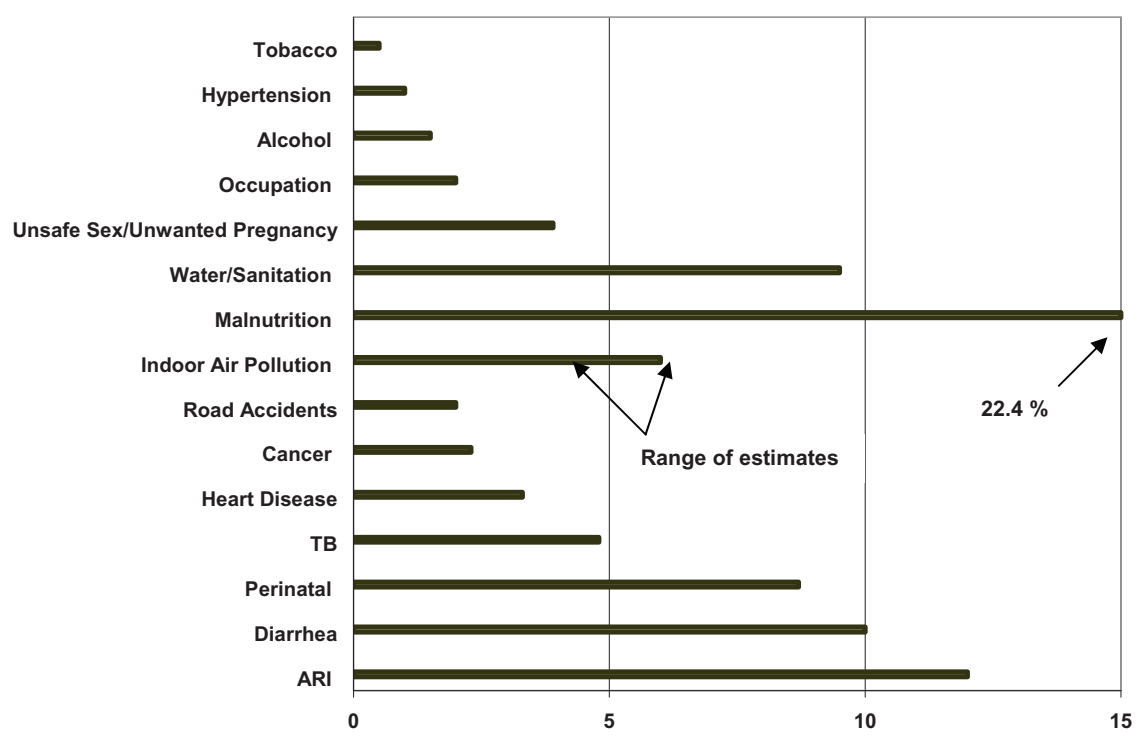

Figure 1: $\quad$ Percentage of national burden of disease (estimated burden of disease (DALYs) in India for selected major risk factors and diseases compared with that from indoor air pollution [3]). 
that the higher indoor concentrations for the homes near higher-traffic areas were primarily influenced by elevated outdoor concentrations. Norback et al. [7] studied the relationship between VOCs, respirable dust, and personal factors to the prevalence and incidence of SBS in six primary schools. This study shows that the average $\mathrm{CO}_{2}$ concentrations in all study sites were greater than $800 \mu \mathrm{l} / 1$ and indicated inadequate ventilation. Gusten and Strindehag [8] have revealed that outdoor pollutant sources play a major role in affecting the IAQ of the school building. The other important factors influencing school building IAQ is the extent of human activities (number of students, length of lessons, breaks) and the premises. Three case studies of IAQ in school buildings were studied by Godish [9]. In the first case, upper respiratory problems and asthma symptoms were reported by students and staff. In the second case, elevated indoor levels of formaldehyde were found due to emissions from pressed wood desks and shelving units. In the third case, mould infestation was inside the school building.

A study by Koo et al. [10] found that the frequency of health symptoms reported by the students learning in air-conditioned classrooms was higher than in naturally ventilated classrooms in Hong Kong.

Lee and Chang [11] investigated the indoor and outdoor air quality of five classrooms that were ventilated by air-conditioners or ceiling fans in Hong Kong. Parameters such as temperature, relative humidity $(\mathrm{RH})$, carbon dioxide $\left(\mathrm{CO}_{2}\right)$, sulphur dioxide $\left(\mathrm{SO}_{2}\right)$, nitric oxide $(\mathrm{NO})$, nitrogen dioxide $\left(\mathrm{NO}_{2}\right)$, respirable particulate matter $\left(\mathrm{PM}_{10}\right)$, formaldehyde $(\mathrm{HCHO})$, and total bacteria counts were monitored indoors and outdoors simultaneously. The average respirable particulate matter concentrations were higher than the Hong Kong standards, and the maximum indoor $\mathrm{PM}_{10}$ level exceeded $1000 \mathrm{mg} / \mathrm{m}^{3}$. The indoor $\mathrm{CO}_{2}$ concentrations often exceeded $1000 \mu \mathrm{l} / 1$ in classrooms with airconditioning and ceiling fans, indicating inadequate ventilation. The study shows that maximum indoor $\mathrm{CO}_{2}$ level reached 5900 ppm during class sessions in the classroom with cooling tower ventilation.

In India, over the last two decades few studies concerning indoor air pollution levels/exposures associated with biomass combustion have been carried out. These studies had very small sample sizes and were not statistically representative of the population. As far as school building IAQ is concerned, very limited studies have been reported. Therefore, in the present study an attempt has been made to assess the IAQ of a school building located close to a busy roadway.

\section{Methodology}

Figure 2 shows the details of the study area selected for the present work. The Kendriya Vidyalaya school building is located within $100 \mathrm{~m}$ of the Madhya Kailash Junction, which is one of the busiest intersections in Chennai City. The school has student strength of 1000 and offers education from pre-school to pre-university level. The classroom selected for the present study is a naturally ventilated room on the first floor. 


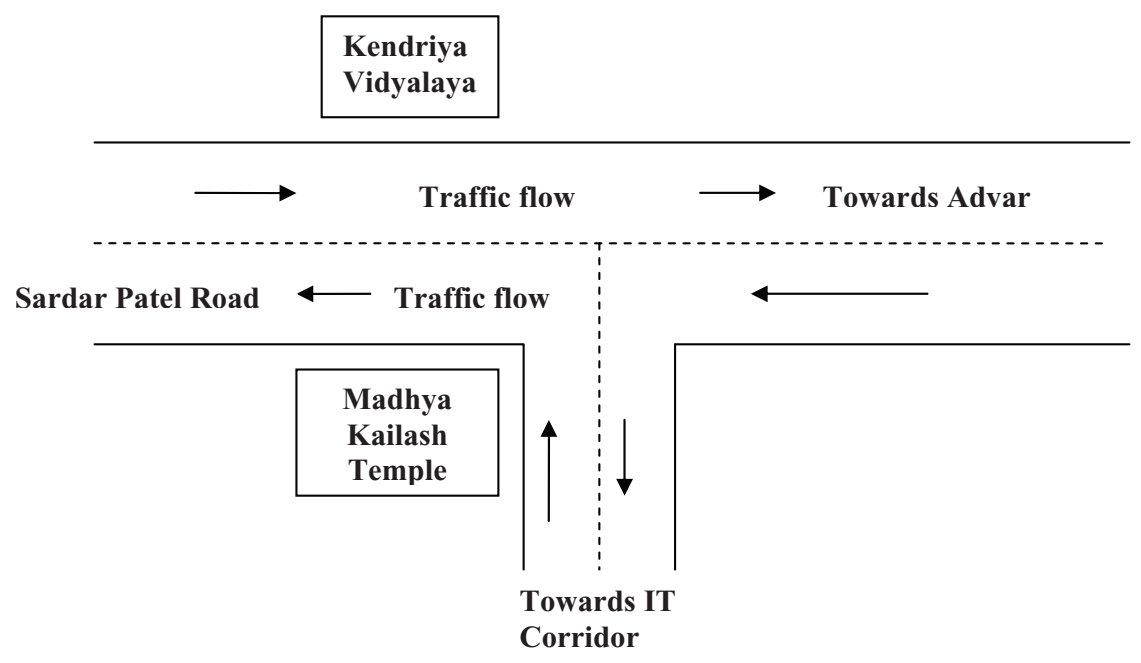

Figure 2: Location of Kendriya Vidyalya school building, Chennai, India.

The IAQ of the naturally ventilated class room is monitored using the IAQ GasProbe instrument (BWM Technologies, Canada). This instrument simultaneously and continuously monitors four parameters, namely $\mathrm{CO}, \mathrm{CO}_{2}$, $\mathrm{RH}$, and temperature (T). The classroom IAQ is monitored for a week in the month of February and April, 2007 for a duration of 5 hours/day (the duration for which students stay inside the classroom.). The data is then transferred to a computer using infra-red light and a data logger. The outdoor $\mathrm{CO}$ concentration is also measured using GasAlert Extreme (BWM Technologies, Canada) for the same duration for which IAQ parameters are monitored.

A questionnaire survey has also been conducted at Kendriya Vidyalaya school among 82 students and 6 teachers. The questions asked in the survey are related to their opinion on classroom comfort levels: ventilation, lighting facilities, cleanliness, temperature, and humidity. The questions also covered the health problems associated with indoor air pollution. The questions asked in the survey are listed in Annexure 1.

\section{Result and discussions}

The survey has been conducted among 82 students and 6 teachers. The students belonged to the age group of $12-15$, in which 45 are female and 37 are male students. The overall results show that more than $80 \%$ of students do not find any air pollution problem inside the building. Figure 3 shows the opinion of the students on their classroom environment. More than $70 \%$ of the students indicated that their classroom environment is above average. The study also shows that more than $50 \%$ of the students show some symptoms of health problems (eye, nasal, throat, chronic respiratory problems) related to indoor air pollution. 
Figure 4 shows the percentage of students having symptoms of health problems, such as nasal, throat, eye, dermatologic problems, aches and pains and chronic respiratory problems. $38 \%$ of students have aches and pains and $21 \%$ of students have eye irritations and nasal problems.

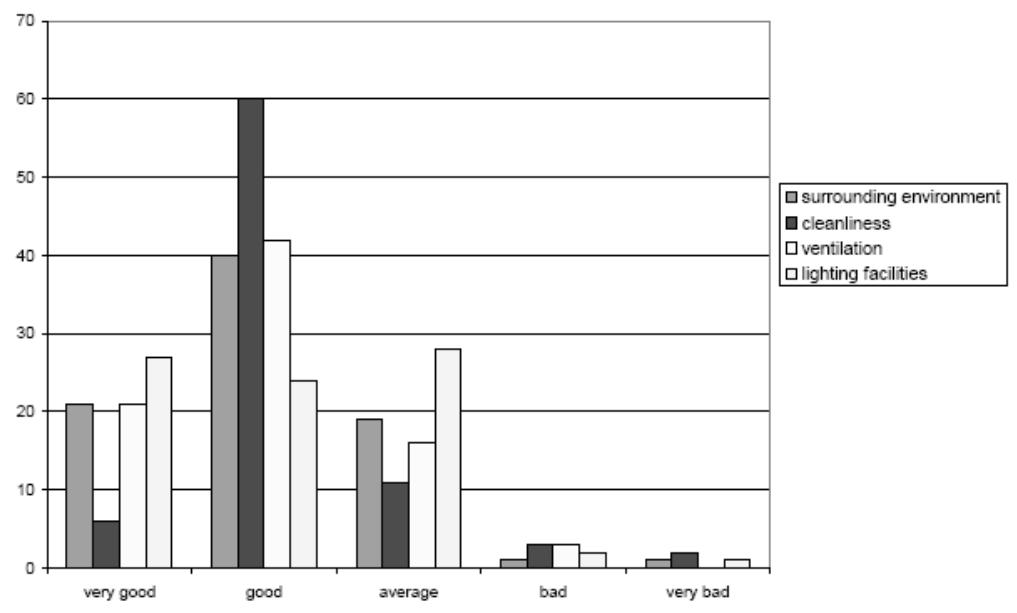

Figure 3: Students' opinion on their classroom environments in Kendriya Vidyalaya school.

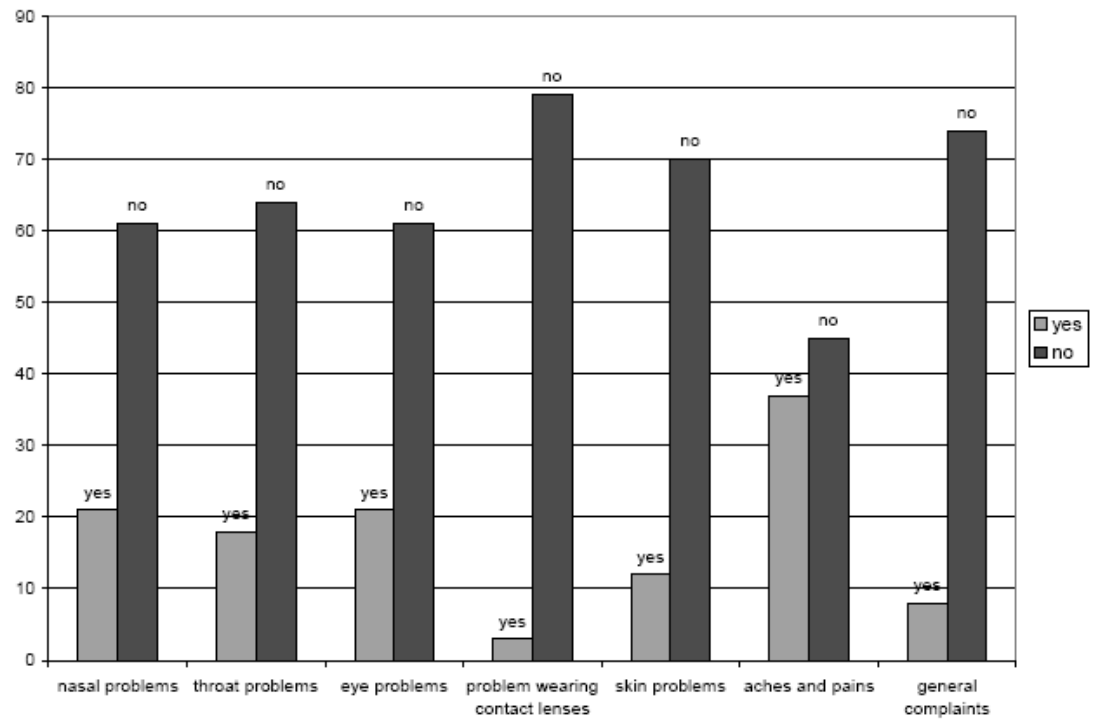

Figure 4: Students' health symptoms in the Kendriya Vidyalaya school. 


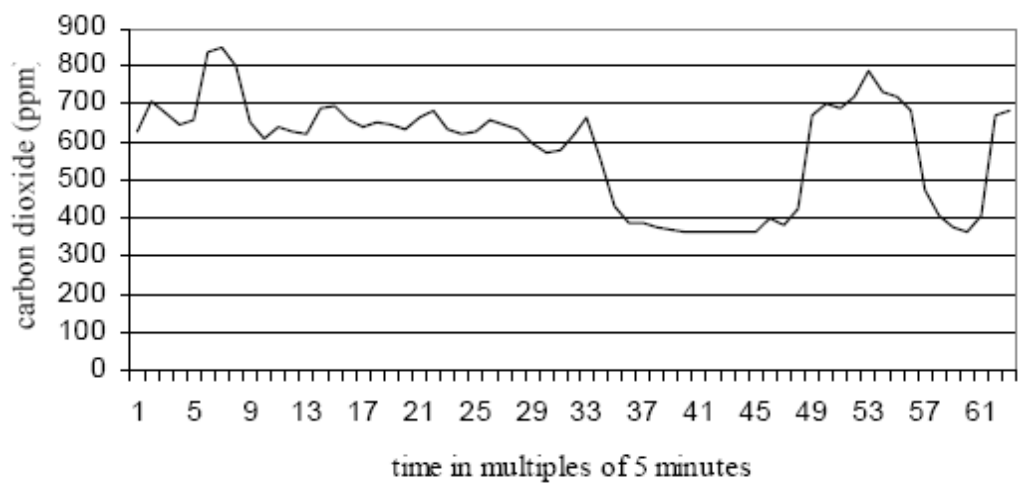

Figure 5: $\quad \mathrm{CO}_{2}$ variations in the Kendriya Vidyalaya school from 9.30 a.m. to 2.50. p.m. on a working day.

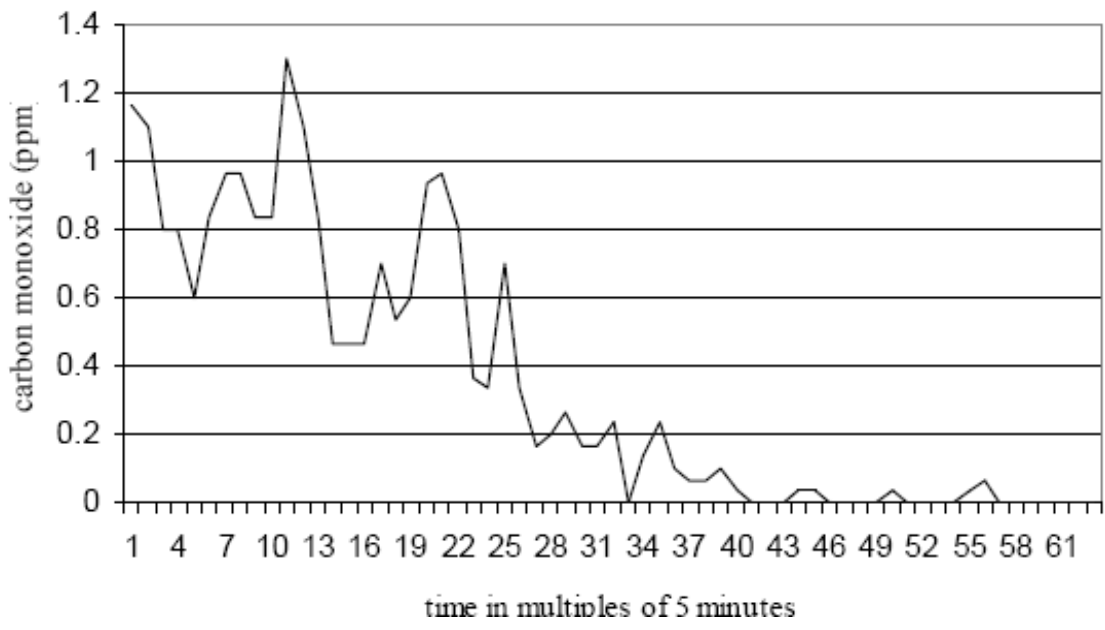

Figure 6: $\quad$ CO variations in the Kendriya Vidyalaya school from 9.30 a.m. to 2.50.p.m. on a working day.

Figure 5 shows the variation of $\mathrm{CO}_{2}$ concentrations in the Kendriya Vidyalaya school building. The peak values of $\mathrm{CO}_{2}$ in the figure are attributed to the increased activities of the students in the classroom during the recesses. The $\mathrm{CO}$ concentration in the classroom was observed only during the peak traffic flow on the adjacent road (Figure 6).

The maximum $\mathrm{CO}_{2}$ and $\mathrm{CO}$ concentrations inside the school building are found to be $927 \mathrm{ppm}$ and $3 \mathrm{ppm}$, respectively. These values do not exceed the threshold values recommended by OSHA (5000 ppm for $\mathrm{CO}_{2}$ and $50 \mathrm{ppm}$ for $\mathrm{CO})$. However, the maximum observed value (927 ppm) of $\mathrm{CO}_{2}$ in the classroom is close to the $1000 \mathrm{ppm}$ threshold recommended by NIOSH. 


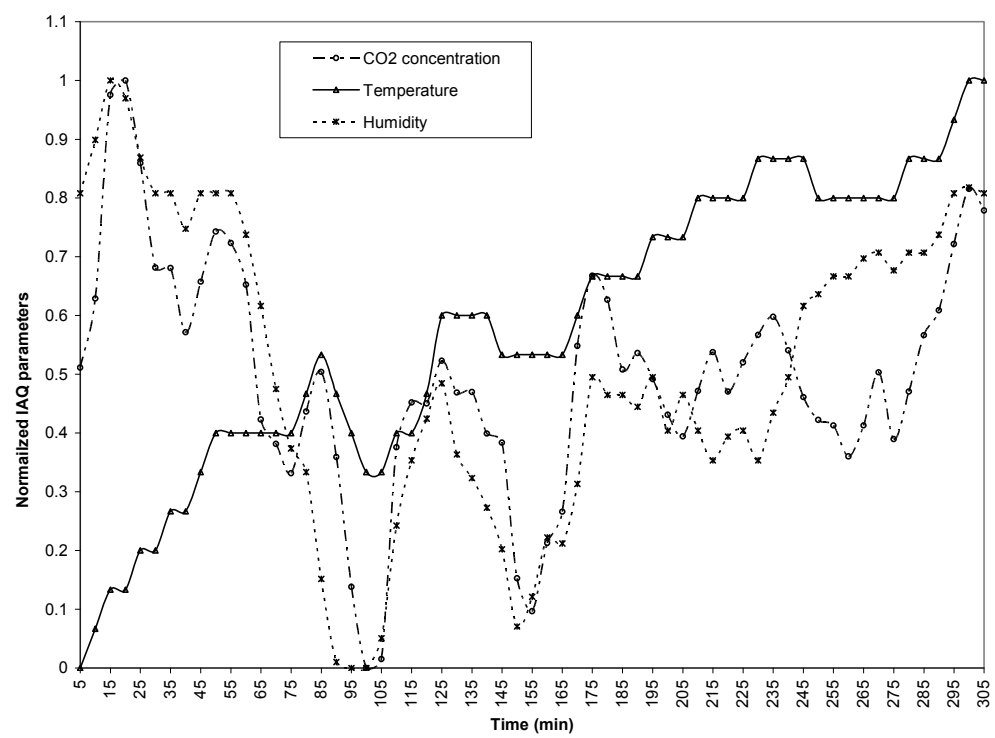

Figure 7: $\quad \mathrm{CO}_{2}$ variations with temperature and relative humidity in the Kendriya Vidyalaya school room.

The multiple regression analysis has been carried out to establish the $\mathrm{CO}_{2}$ dependency with humidity and temperature. It is found that when $\mathrm{CO}_{2}$ is regressed with only relative humidity and only temperature, the $\mathrm{R}^{2}$ value ranges from 0.1 to 0.6 and 0.1 to 0.4 , respectively. The $\mathrm{CO}_{2}$ showed good correlation when it regressed with both humidity and temperature $\left(\mathrm{R}^{2}\right.$ value range from 0.3 to 0.8 ). Figure 7 presents the $\mathrm{CO}_{2}$ variations with humidity and temperature.

\section{Conclusions}

In the present study the IAQ of the classroom of the school building (Kendriya Vidyalaya) has been studied. The IAQ parameters, namely $\mathrm{CO}_{2}, \mathrm{CO}$, humidity and temperature have been measured using an IAQ monitor for one week in the months of February and April, 2007 in the study region. The results show that the maximum $\mathrm{CO}_{2}$ concentration in the school building is found to be $927 \mathrm{ppm}$, which is close to the $1000 \mathrm{ppm}$ threshold recommended by NIOSH. This indicates that the ventilation of the school is not sufficient. The $\mathrm{CO}_{2}$ dependency with only temperature and with only relative humidity are found to be $\mathrm{R}^{2}=0.349$ and 0.562 , respectively. From the questionnaire survey it is found that students have some symptoms of health problems.

This study also shows that the indoor CO concentrations are higher during peak hour traffic flow on the adjacent road. 


\section{Annexure 1}

\section{Questionnaire for indoor air quality in school building}

1. Age

2. Gender ----- M/F

3. Mode of transportation to school

Bus

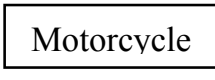

Auto

Car

4. Time taken for reaching school from house (mins)

5. Time taken for reaching home from school (mins)

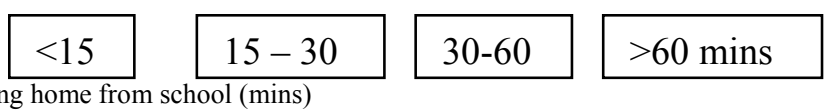

6. Time spent inside the classroom in a day (hrs)
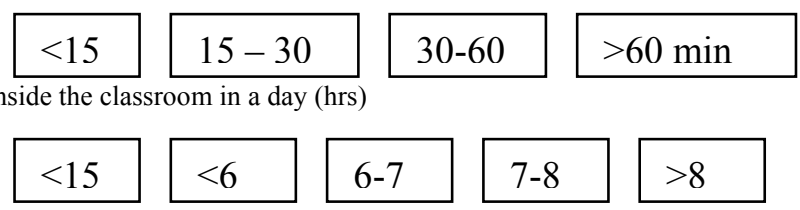

7. Is the temperature in your classroom comfortable --- Yes / No

if No what are the reasons

8. Is the humidity in your classroom comfortable --- Yes / No

if No what are the reasons

9. Surrounding environment of the school building-very good/good/average/bad/very bad

10. Cleanliness inside the classroom ---- very good / good / average / bad / very bad

11. Ventilation inside the classroom---- very good / good / average / bad / very bad

12. Lighting facilities inside the classroom---- very good / good / average / bad / very bad

13. What health problems are you experiencing?

14. Do you suffer from chronic respiratory problems (asthma, bronchitis, etc) - $\mathrm{Yes} / \mathrm{No}$ If Yes please mention it

15. Are you currently under any regular medication ----Yes / No If yes for what are taking medicines and since how long

16. Do you observe any odour in your classroom --- Yes/ No If Yes how long does it persist in a day

17. Are you experiencing any air pollution problem inside the class room --- Yes / No

18. Do you think outside vehicular air pollution is affecting the indoor environment of your classroom ---Yes / No 


\begin{tabular}{|c|c|c|c|c|}
\hline $\begin{array}{c}\text { Sl. } \\
\text { No }\end{array}$ & Symptoms of the problem & YES & NO & $\begin{array}{c}\text { How long } \\
\text { did these symptoms } \\
\text { last (hrs/days) }\end{array}$ \\
\hline $13 \mathrm{a}$ & $\begin{array}{c}\text { Nasal problems: nose bleeding, } \\
\text { sinus problem, sneezing, runny } \\
\text { nose, dry nose. }\end{array}$ & & & \\
\hline $13 \mathrm{~b}$ & $\begin{array}{c}\text { Throat symptoms: sore throat, dry } \\
\text { cough, etc. }\end{array}$ & & & \\
\hline $13 \mathrm{c}$ & $\begin{array}{c}\text { Eye symptoms: redness, burning, } \\
\text { watering, dryness, irritation in eye } \\
\text { or blurred vision. }\end{array}$ & & & \\
\hline $13 \mathrm{~d}$ & $\begin{array}{c}\text { Problems wearing contact lenses: } \\
\text { discomfort, burning, pain in eyes. }\end{array}$ & & & \\
\hline $13 \mathrm{e}$ & $\begin{array}{c}\text { Dermatology problems: skin } \\
\text { irritation, dryness, flakiness, } \\
\text { dandruff in hair. }\end{array}$ & & & \\
\hline $13 \mathrm{f}$ & $\begin{array}{c}\text { Aches and pains: headaches, } \\
\text { migraines, muscle or joint pains. }\end{array}$ & & & \\
\hline $13 \mathrm{~g}$ & $\begin{array}{c}\text { General complaints: drowsiness, } \\
\text { dizziness, faintness, breathing } \\
\text { problems, digestive problems. }\end{array}$ & & & \\
\hline
\end{tabular}

\section{References}

[1] World Health Organization (WHO), Indoor Air Pollution from Biomass Fuel, WHO/PEP 92-93A. Geneva, 1992.

[2] World Health Organization (WHO), The Health Effects of Indoor Air Pollution Exposure in Developing Countries, Geneva, 2002.

[3] Smith, K.R., National burden of disease in India from indoor air pollution. Proceedings of the national academy of sciences, 97, pp. 13286-13293, 1997.

[4] Kostiainen, R., Volatile organic compounds in the indoor air of normal and sick houses. Atmospheric Environment, 29(6) 693-702, 1995.

[5] Berglund, B., Brunekreef, B., Knoppel, H., Lindvall, T., Maroni, M., Millhave, L. \& Skov. P., Effects of indoor air pollution on human health. Indoor Air, 2 (1), pp 2-25, 1992

[6] Fischer, P.H., Hoek, G., Van Reeuwijk, H., Briggs, D.J., Lebret, E., Van Wijnen, J.H., Kingham, S. \& Elliott, P.E., Traffic-related differences in outdoor and indoor concentrations of particles and volatile organic compounds in Amsterdam. Atmospheric Environment, 34, 3713-3722, 2000 .

[7] Norback, D., Torgen, M. \& Edling, C., Volatile organic compounds, respirable dust and personal factors related to prevalence and incidence of sick building syndrome in primary schools. British Journal of Industrial Medicine, 47, pp. 733-741, 1990. 
[8] Gusten, J. \& Strindehag, O., Experiences of measures taken to improve the air quality in schools. Air Infiltration Review 16, pp. 5-8, 1995

[9] Godish, T.J., (1996). Indoor air contamination problems in school buildings. Air \& Waste Management Association Annual. Meet. 96WP85.05, Toronto, Canada, 1996.

[10] Koo, L.C.L., Luk, M.Y., Mok, M.Y., Yuen, J.H.F., \& Yuen, T.Y.S., Health effects from air conditioning: epidemiologic studies on schools and offices in Hong Kong. Proceedings of Indoor and Built Environment Problems in Asia, Kuala Lumpur, Malaysia, pp. 76 -86, 1997

[11] Lee, S.C., Chang, M., Indoor and outdoor air quality investigation at schools in Hong Kong. Chemosphere, 41, pp.109-113, 2000. 